\title{
Source-Sink Partitioning of Mineral Nutrients and Photo-assimilates in Tomato Plants Grown under Suboptimal Nutrition
}

\author{
Jwakyung Sung, Suyeon Lee ${ }^{\dagger}$, Yejin Lee, Hongbae Yun, Sangkeun Ha, and Yongsik $\mathrm{Ok}^{1 *}$ \\ Division of Soil and Fertilizer Management, NAAS, RDA, Suwon, 441-707, Korea \\ ${ }^{I}$ Department of Biological Environment, Kangwon National University, Chuncheon, 200-710, Korea
}

(Received: November 5 2013, Accepted: December 11 2013)

\begin{abstract}
A huge number of greenhouse soils in Korea have accumulated mineral elements which induce many nutritional and pathological problems. The present study was performed to the effects of the reduced fertilization on plant growth, and uptake and partitioning of minerals (N, P, K) and soluble carbohydrates using highly minerals-accumulated farmer's greenhouse soil. On the basis of the recommended application for tomato crop, the application rates of $\mathrm{N}, \mathrm{P}$ and $\mathrm{K}$ were $110(50 \%)-5.2(5 \%)-41.5(35 \%) \mathrm{kg}$ ha $^{-1}$, respectively, using Hoagland's nutrient solution. Tomato growth rates during the whole experiment were not significant between treatments, but it was found that a decrease in daily growth represented after 60 days of treatment (DAT). The reduced application led to a drastic decrease in the concentration of $\mathrm{N}, \mathrm{P}$ and $\mathrm{K}$ in fruits, and,thus, this resulted in lower uptake after $40 \mathrm{DAT}$. The lower phloem export and utilization of soluble carbohydrates caused an accumulation of extra-carbohydrates in leaves, stems and fruits in the reduced application. The reduced fertilization induced the capture of $\mathrm{N}, \mathrm{P}$ and $\mathrm{K}$ in leaves and of soluble carbohydrates in stems compared to the conventional application. In this study, we suggest that it is possible to delay the first fertigation time in minerals-accumulated soils without an adverse impact on crop growth, but it is necessary to regularly monitor mineral status in soil to ensure a balanced uptake, synthesis and partitioning of minerals and carbohydrates.
\end{abstract}

Key words: Tomato, Mineral, Carbohydrates, Assimilates partitioning
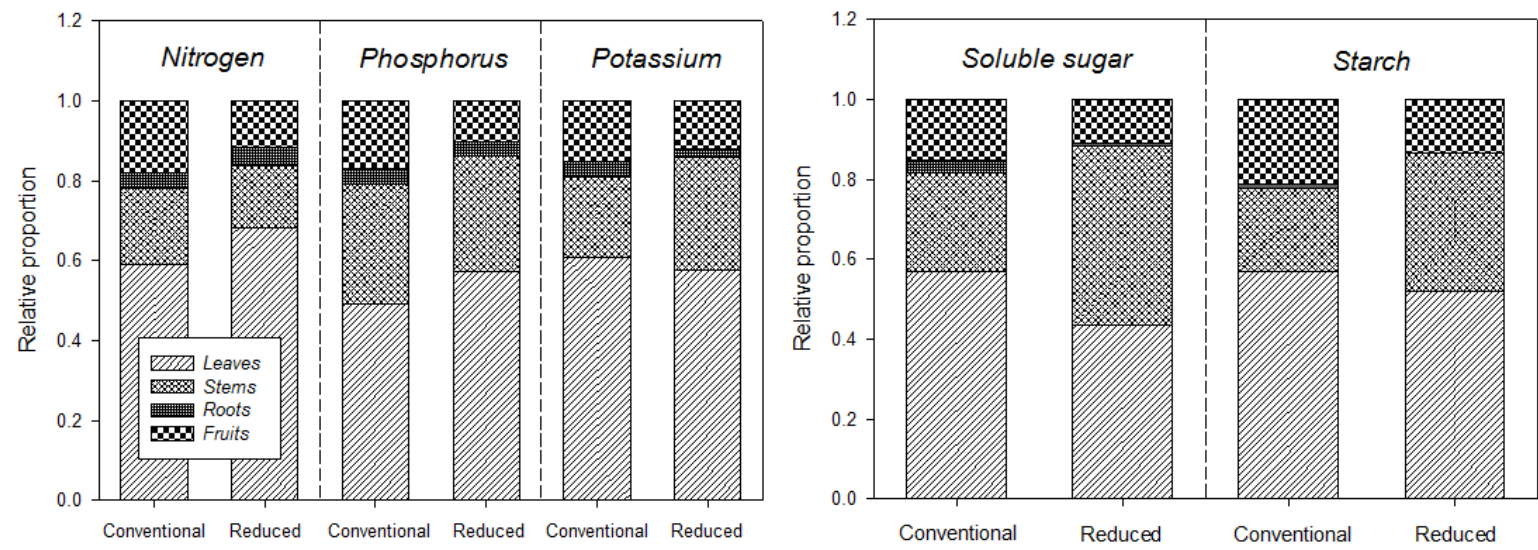

Relative proportion of minerals and soluble carbohydrates by tomato organs.

Our data report whether the reduced mineral application in highly mineral accumulated-soils affects crop growth and mineral uptake, and how minerals and soluble carbohydrates are partitioned to plant organs under suboptimal nutrition condition.

\footnotetext{
*Corresponding author : Phone: +82332506443, Fax: +82332416640, E-mail: soilok@kangwon.ac.kr

$\dagger$ An author contributed equally to this work and is considered as a co-first author.

${ }^{\S}$ Acknowledgement: This work was financially supported by the by a grant from the research project (No. PJ008596) of National Academy of Agricultural Science, Rural Development Administration, Republic of Korea.
} 


\section{Introduction}

Protected cultivation in greenhouses has been widely used during the growing whole season for many vegetative crops. However, incorrect fertilizer application in greenhouse has led to severe soil salinization and limited crop productivity since last few decades (Atallah et al., 2002; Yu et al., 2004). Generally, fertilizers were usually applied to soils regardless of soil nutrient conditions and plant requirement in an equal nitrogen, phosphorus and potassium formulation (Atallah et al., 2000); finally, the excessive nutrients which were accumulated in soils made it difficult that plants absorb conveniently. The limited understanding of the mechanisms that govern the partitioning of carbohydrates and mineral nutrients between different plant organs is considered to be the main factor restricting the development of processbased modeling of whole plant growth (Dewar, 1993; Cannell and Dewar, 1994). The growth is strongly affected by the supply of carbon from the shoot and minerals, especially nitrogen, from the root. Preferential partitioning of photosynthetic carbon to the roots and increase in root-shoot dry weight ratio are well documented for plants under nitrogen and phosphorus deficiency (Fredeen et al., 1989; Levin et al., 1989; Cakmak, 1994; Peuke et al., 1994).

The South Korea Government (Ministry of Agriculture, Food and Rural Affairs) has driven the agricultural policy which the use of chemical fertilizers is to reduce gradually up to $35 \%$ until 2022 relative to $2010\left(242 \mathrm{~kg} \mathrm{ha}^{-1}\right)$. According to the result of monitoring an agro-environmental quality for greenhouse soils (NAAS, 2012), soil chemical properties except for $\mathrm{pH}$ represented significantly higher compared to the recommended critical level, and, especially, more than $80 \%$ of monitored greenhouse soils excessively accumulated available phosphorus. Furthermore, the soil EC which is an indicator of salt concentration exceeded more than $55 \%\left(>2.0 \mathrm{dS} \mathrm{m}^{-1}\right)$ which could provoke salt stress in greenhouse soils.

Most greenhouse farmers are initiating the fertigation (fertilization + irrigation) after approximately 2 weeks of transplanting, and it sometimes cause salt accumulation in soil and nutritional disorder of crops. Thus, it is necessary to investigate the growth and mineral utilization pattern of crop for achieving the enhancement of soil-deposited mineral use and the reduction in fertilization. The objectives of this study were: (1) to examine whether the reduced mineral application in highly mineral accumulated-soils affects crop growth and mineral uptake, and (2) to understand how minerals and soluble carbohydrates are partitioned to plant organs under suboptimal nutrition condition.

\section{Materials and Methods}

Plant materials and growth conditions The present study was performed in a green house in National Academy of Agricultural Science in Suwon, South Korea in 2013. Seeds of tomato (Lycopersicon esculentum cv. Seonmyoung) were germinated in a tray filled with perlite supplied with distilled-deionized water, and, a week later, seedlings were transplanted into a commercial nursery soil (Seoul-Bio Co. Ltd., South Korea). Three weeks later, the uniformly growing tomato seedlings were transferred into $15 \mathrm{~L}$ plastic box filled with farmland soils (see Table 1), and then fed with complete Hoagland's solution media; $5 \mathrm{mmol} \mathrm{L}^{-1}$ $\mathrm{Ca}\left(\mathrm{NO}_{3}\right)_{2} \cdot 4 \mathrm{H}_{2} \mathrm{O}, 5 \mathrm{mmol} \mathrm{L}^{-1} \mathrm{KNO}_{3}, 2 \mathrm{mmol} \mathrm{L}^{-1} \mathrm{MgSO}_{4}$ - $7 \mathrm{H}_{2} \mathrm{O}, 0.5 \mathrm{mmol} \mathrm{L}^{-1} \mathrm{KH}_{2} \mathrm{PO}_{4}, 1.5 \mathrm{mmol} \mathrm{L}^{-1}$ Fe-EDTA, $1 \mathrm{mmol} \mathrm{L} \mathrm{NH}_{4} \mathrm{NO}_{3}$, and $1 \mathrm{~mL}$ of micro-elements mixture $\left(\mathrm{H}_{3} \mathrm{BO}_{3}, 2.86 \mathrm{~g} \mathrm{~L}^{-1} ; \mathrm{MnCl}_{2} \cdot 4 \mathrm{H}_{2} \mathrm{O}, 1.81 \mathrm{~g} \mathrm{~L}^{-1} ; \mathrm{ZnSO}_{4} \cdot\right.$ $7 \mathrm{H}_{2} \mathrm{O}, 0.22 \mathrm{~g} \mathrm{~L}^{-1} ; \mathrm{CuSO}_{4} \cdot 5 \mathrm{H}_{2} \mathrm{O}, 0.051 \mathrm{~g} \mathrm{~L}^{-1} ; \mathrm{H}_{2} \mathrm{MoO}$. $4 \mathrm{H}_{2} \mathrm{O}, 0.09 \mathrm{~g} \mathrm{~L}^{-1}$ ). On the basis of the recommended fertilization rates (for tomato plants (NAAS, 2010), the conventional application was finally decided with $\mathrm{N}, \mathrm{P}$ and $\mathrm{K}\left(220-10.3-83 \mathrm{~kg} \mathrm{ha}^{-1}\right)$ with an application of soil depth $(15 \mathrm{~cm})$ and bulk density $\left(1.2 \mathrm{~g} \mathrm{~cm}^{-3}\right)$. Every 3 days supply was considered as a conventional interval based on the farmer's practice, and the Hoagland's solution for the reduced treatment (half level of the conventional) was supplied every 6 days.

\section{Mineral element measurements and mineral uptake} A sample of four plants which taken every 20 days was separated into leaves, stems and roots, washed with tap water followed by distilled water, oven-dried at $80^{\circ} \mathrm{C}$ for $48 \mathrm{~h}$, and then weighed. The dry samples were ground to pass through a $0.5-\mathrm{mm}$ screen using an electric grind machine. The dried leaves, stems and roots (each $0.5 \mathrm{~g}$ ) were soaked in $5 \mathrm{~mL}$ of $368 \mathrm{mM}$ salicylic acid in $84.7 \%$

Table 1. Chemical properties of the soil used in this study.

\begin{tabular}{|c|c|c|c|c|c|c|c|c|c|c|c|c|}
\hline \multirow{2}{*}{ Time } & \multirow{2}{*}{ Treatment } & $\mathrm{pH}$ & $\mathrm{EC}$ & O.M. & T-N & $\mathrm{NO}_{3}^{-}-\mathrm{N}$ & $\mathrm{NH}_{4}{ }^{+}-\mathrm{N}$ & Av. $\mathrm{P}_{2} \mathrm{O}_{5}$ & \multicolumn{4}{|c|}{ Ex. cations $\left(\mathrm{cmol}^{+} \mathrm{kg}^{-1}\right)$} \\
\hline & & $(1: 5, \mathrm{w} / \mathrm{v})$ & $\mathrm{dS} \mathrm{m}^{-1}$ & ---- g & $\mathrm{kg}^{-1}----$ & - n & $-\mathrm{mg} \mathrm{kg}^{-1}$ & 1 --------- & $\mathrm{K}$ & $\mathrm{Ca}$ & $\mathrm{Mg}$ & $\mathrm{Na}$ \\
\hline Before & - & $7.5 \pm 0.1$ & $6.0 \pm 0.1 \mathrm{~b}$ & $30 \pm 1$ & $1.4 \pm 0.0 \mathrm{a}$ & 124 & 53 & $1,101 \pm 42 \mathrm{a}$ & $1.7 \pm 0.1 \mathrm{a}$ & $11.2 \pm 0.2 \mathrm{c}$ & $5.3 \pm 0.1 \mathrm{~b}$ & $0.9 \pm 0.1 b$ \\
\hline \multirow{2}{*}{$\dagger$ After } & Conventional & $7.3 \pm 0.1$ & $7.2 \pm 0.2 \mathrm{a}$ & $29 \pm 2$ & $1.2 \pm 0.0 \mathrm{~b}$ & - & - & $848 \pm 6 c$ & $0.6 \pm 0.0 \mathrm{c}$ & $14.9 \pm 0.2 \mathrm{a}$ & $5.8 \pm 0.1 \mathrm{a}$ & $1.6 \pm 0.1 \mathrm{a}$ \\
\hline & Reduced & $7.5 \pm 0.1$ & $3.8 \pm 0.1 \mathrm{c}$ & $30 \pm 2$ & $1.2 \pm 0.0 \mathrm{~b}$ & - & - & $913 \pm 10 b$ & $0.8 \pm 0.0 \mathrm{~b}$ & $12.4 \pm 0.1 \mathrm{~b}$ & $4.6 \pm 0.1 \mathrm{c}$ & $0.9 \pm 0.1 \mathrm{~b}$ \\
\hline
\end{tabular}

$\dagger$ The experiment was performed for 80 days and soil chemical properties were analyzed after the experiment. 
sulfuric acid $\left(\mathrm{H}_{2} \mathrm{SO}_{4}\right)$ for $24 \mathrm{~h}$ then digested in a digestion system, heated to $300^{\circ} \mathrm{C}$ for $3 \mathrm{~h}$, followed by several drops of hydrogen peroxide $\left(\mathrm{H}_{2} \mathrm{O}_{2}\right)$. The extracted solution was transferred to $100 \mathrm{~mL}$ volumetric flasks and then diluted to $100 \mathrm{~mL}$ with deionized water for mineral assays. The $\mathrm{N}$ concentration was colorimetrically determined using the automatic flow injection analyzer (BRAN LUBBE, Germany). The $\mathrm{P}$ concentration was measured using the molybdate-blue colorimetry method (UV-2450, Shimadzu, Japan) and cation concentrations were determined with ICP-OES (INTEGRA XMP, GBC, Australia). The uptake rates of $\mathrm{N}, \mathrm{P}$, and $\mathrm{K}$ were estimated using growth rate (dry weight) and mineral concentration.

$\mathrm{CO}_{2}$ Assimilation Measurements Photosynthetic activities in response to different EC levels were measured with a

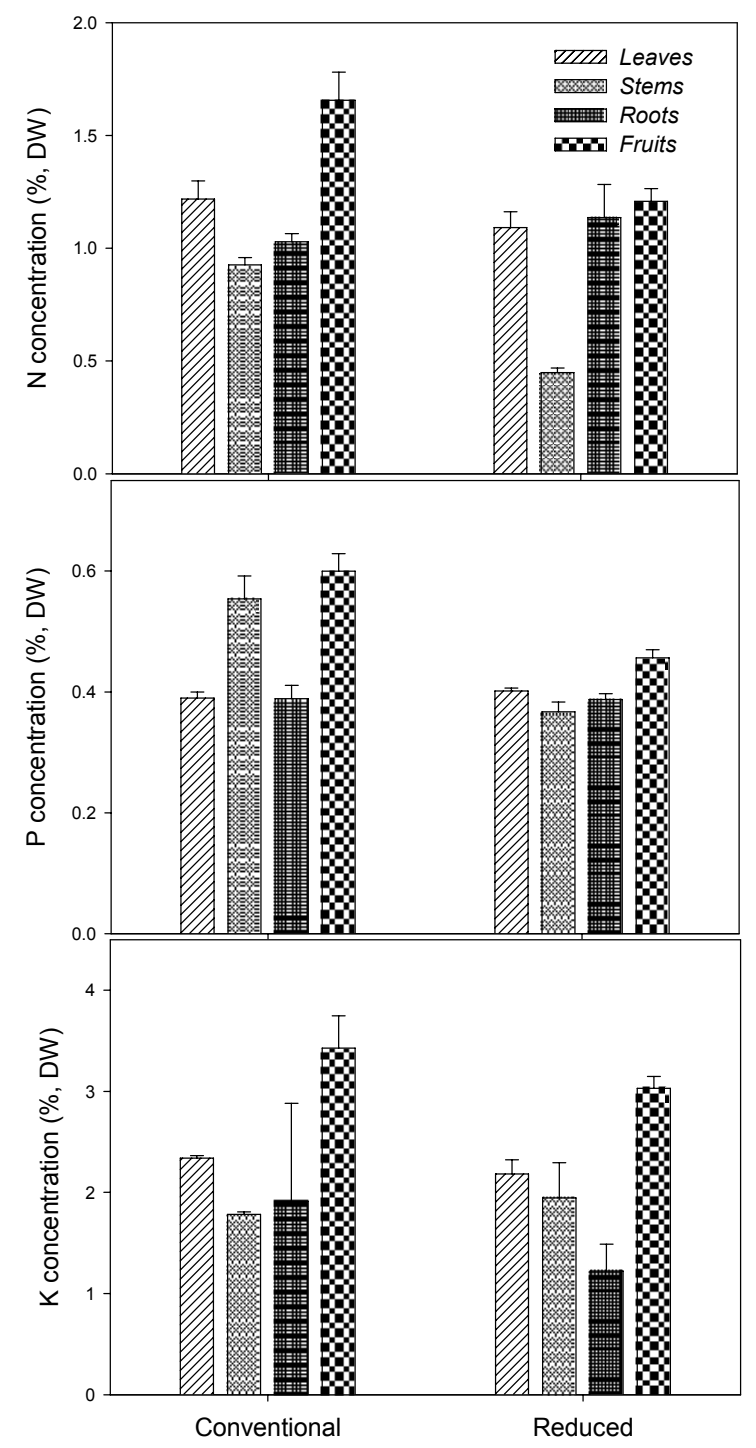

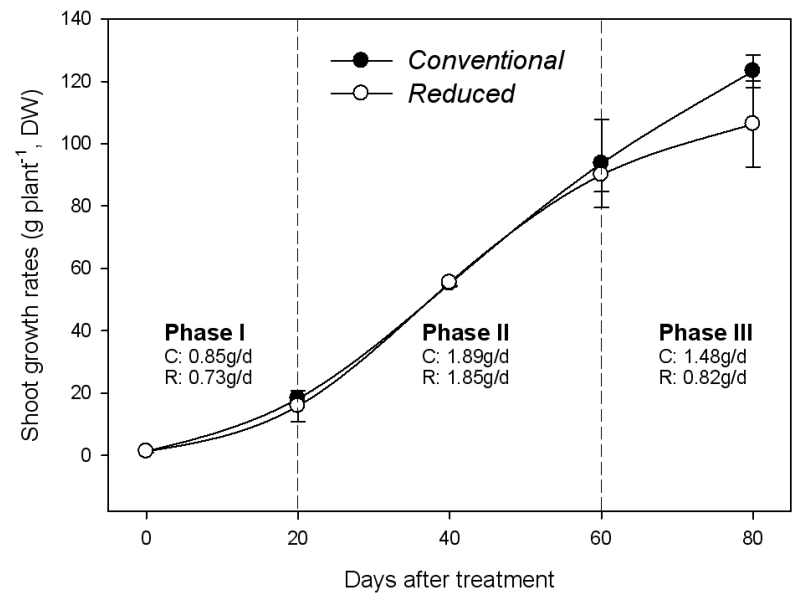

Fig. 1. Effect of the reduced supply of mineral nutrition on shoot dry weight of tomato plants. Error bars indicate standard deviations of four replicates.

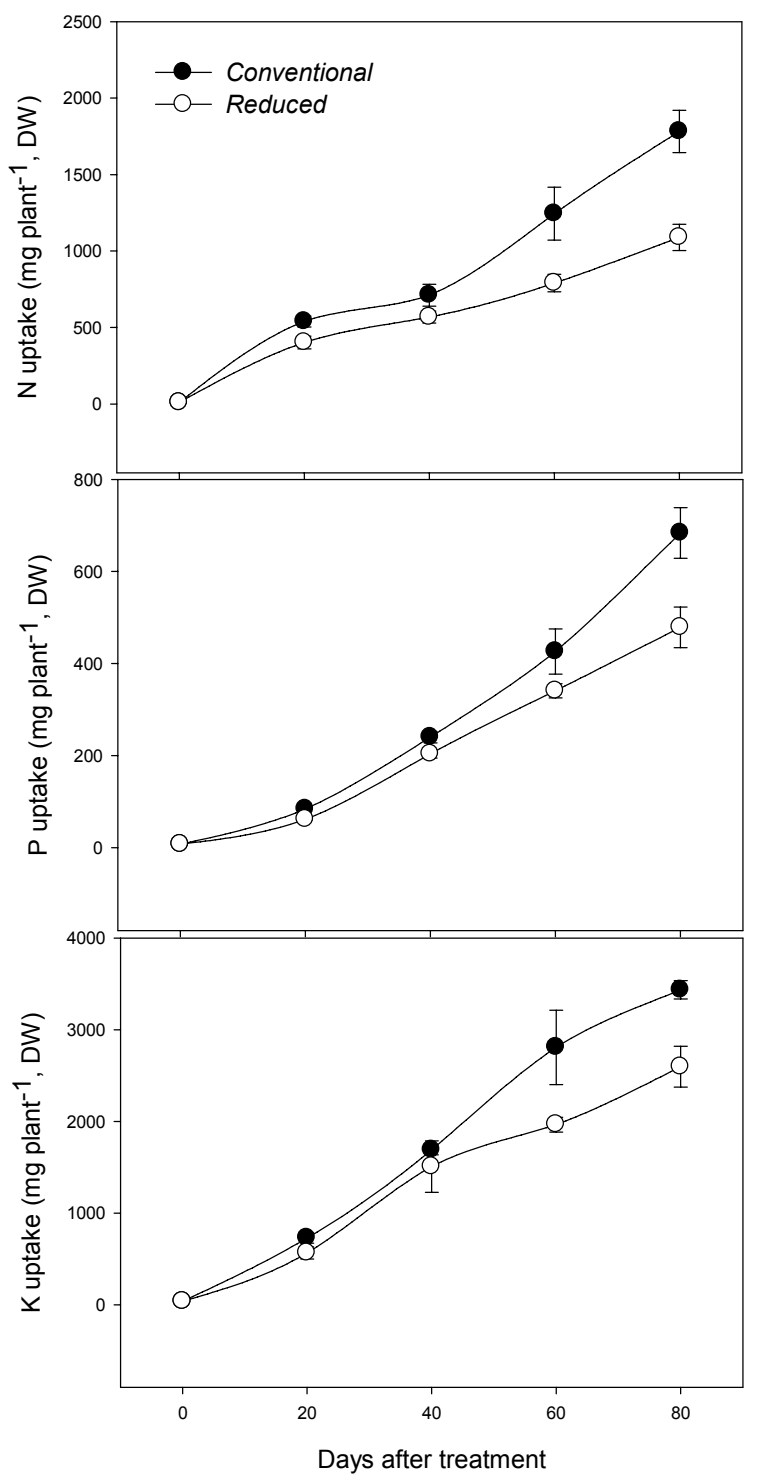

Fig. 2. Effects of the reduced supply of mineral nutrition on nutrient concentrations (\%, dry weight) at 80 days after mineral supply and uptake (sum of leaves, stems, roots, and fruits, mg plant $^{-1}$, DW) of tomato plants. Error bars indicate standard deviations of four replicates. 


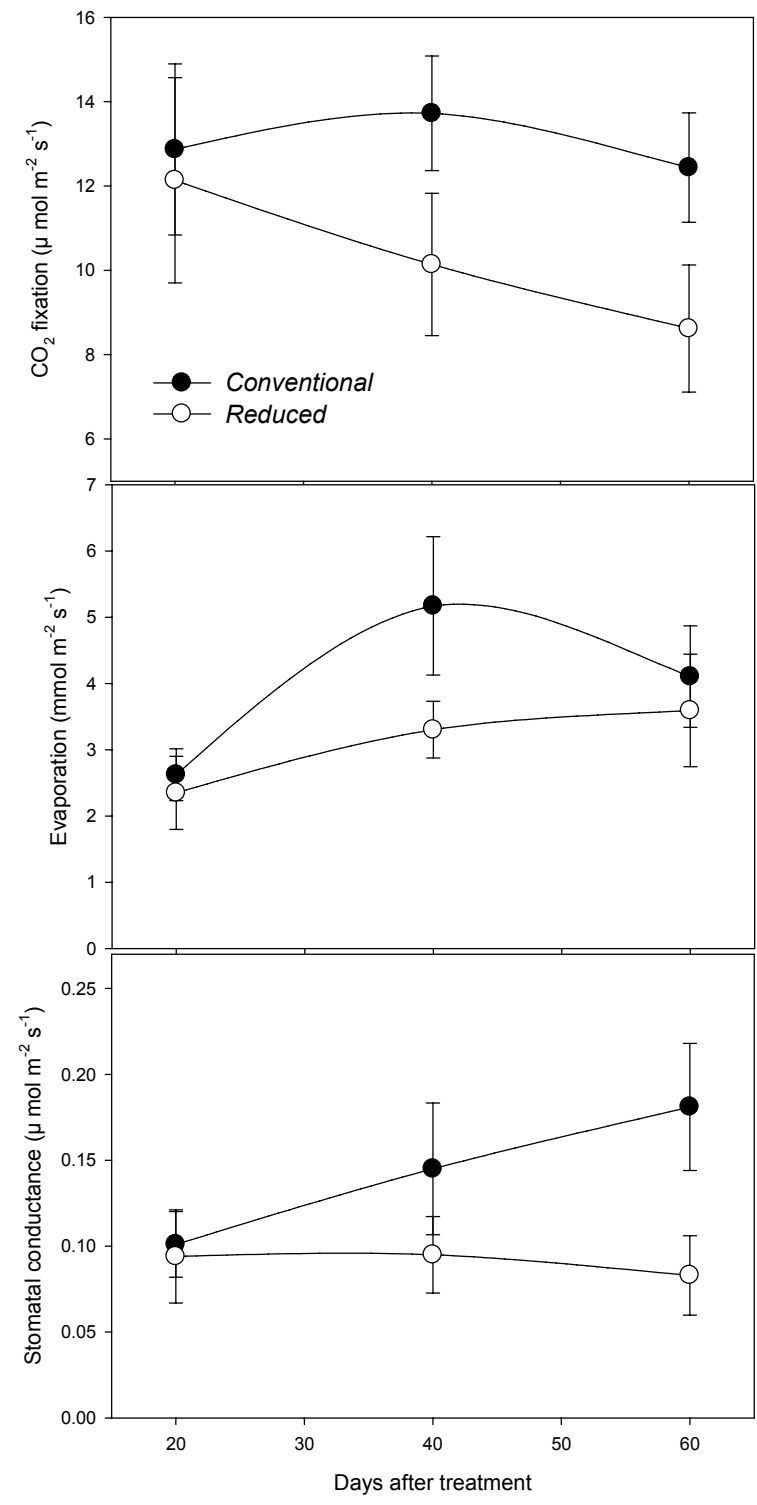

Fig. 3 Effects of the reduced supply of mineral nutrition on $\mathrm{CO}_{2}$ fixation, evaporation rates and stomatal conductance of tomato plants. Emor bars indicate standard deviations of four replicates.

$\mathrm{CO}_{2}$ analyzer (ADC LCpro ${ }^{+}$ADC BioScientific Ltd, UK) operating in a differential mode. Mid-fully expanded tomato leaves from each treatment were enclosed in the square $\left(6.25 \mathrm{~cm}^{2}\right)$ chamber to monitor $\mathrm{CO}_{2}$ assimilation $(A)$, transpiration rate $(E)$ and stomatal conductance $\left(g_{s}\right)$. Photosynthesis measurement with PPFD (800-1,100 $\left.\mu \mathrm{mol} \mathrm{m} \mathrm{m}^{-2} \mathrm{~s}^{-1}\right)$ and atmosphere $\mathrm{CO}_{2}\left(380 \pm 10 \mu \mathrm{mol} \mathrm{m}{ }^{-2}\right)$ were performed between 10:00 and 14:00.

Soluble carbohydrate measurements Soluble sugar (glucose equivalent) from fresh leaves and roots were determined by the reaction of $1.0 \mathrm{~mL}$ of the alcoholic extract with $2.0 \mathrm{~mL}$ fresh $0.2 \%$ anthrone in sulfuric acid $(\mathrm{w} / \mathrm{v})$; the absorbance was read at $630 \mathrm{~nm}$. After the extraction of the soluble fractions, the solid fraction was used for starch analysis. Starch was extracted with $9.3 \mathrm{~mol} \mathrm{~L}^{-1}$ perchloric acid followed by $4.6 \mathrm{~N}$. The extracts were combined and starch concentration was determined after reaction with the anthrone reagent. Glucose was used as the standard for soluble sugars.

Statistical analysis The ANOVA was conducted to find effects of treatments using version 9.01 of SAS (SAS Institute Inc, Cary, NC). The significance of the treatment effect was determined using Fisher's protected test. To determine the significance of the difference between the means of treatments, least significant difference (LSD) was computed at the $5 \%$ probability level.

\section{Results}

Growth of tomato plants The dry weight from each treatment was shown in Fig. 1. The shoot growth rates of tomato plants based on dry weight was no significant $(P<0.05)$ throughout the whole experiment. Three growth phases which represented different growth rates were found; the conventional application showed the increase in dry weight of 0.85 (0-20 DAT)-1.89 (20-60 DAT)-1.48 (60-80 DAT) g per day, whereas the reduced was $20 \%$ lower on average compared to the conventional.

Nutrient concentration and uptake in different organs of tomato plants Concentrations and uptake of mineral elements $(\mathrm{N}, \mathrm{P}$ and $\mathrm{K})$ in the shoots at 80 DAT were strongly affected by the reduced treatment of mineral nutrition, but not in roots (Fig. 2). Moreover, the concentration in mineral elements varied with plant organs; nitrogen and phosphorus in stems and fruits were less accumulated by the reduced treatment whereas potassium did not show a statistic difference between treatments. The uptake of mineral elements was extremely dependent upon the concentration, and the effect of dry weight of tomato plants was partial. In addition, it was not observed a considerable difference in their uptake until 40 DAT, but showed a substantial gap between treatments from 40 DAT as the meaningful difference took place. The uptake rates of $\mathrm{N}, \mathrm{P}$ and $\mathrm{K}$ in the conventional treatment were 1,782, 684 and 3,434 mg per plant, respectively, whereas, in the reduced, $1,089(61 \%$, relative to the conventional), $479(70 \%)$ and $2,596(76 \%)$ mg per plant, respectively.

Photosynthesis and soluble carbohydrates accumulation The $\mathrm{CO}_{2}$ fixation differed significantly between treatments (Fig. 3), and the conventional treatment showed constant range (12.5 to $13.7 \mu \mathrm{mol} \mathrm{m} \mathrm{m}^{-2}$ ), whereas the reduced decreased gradually with an increase in growth (12.2 to 

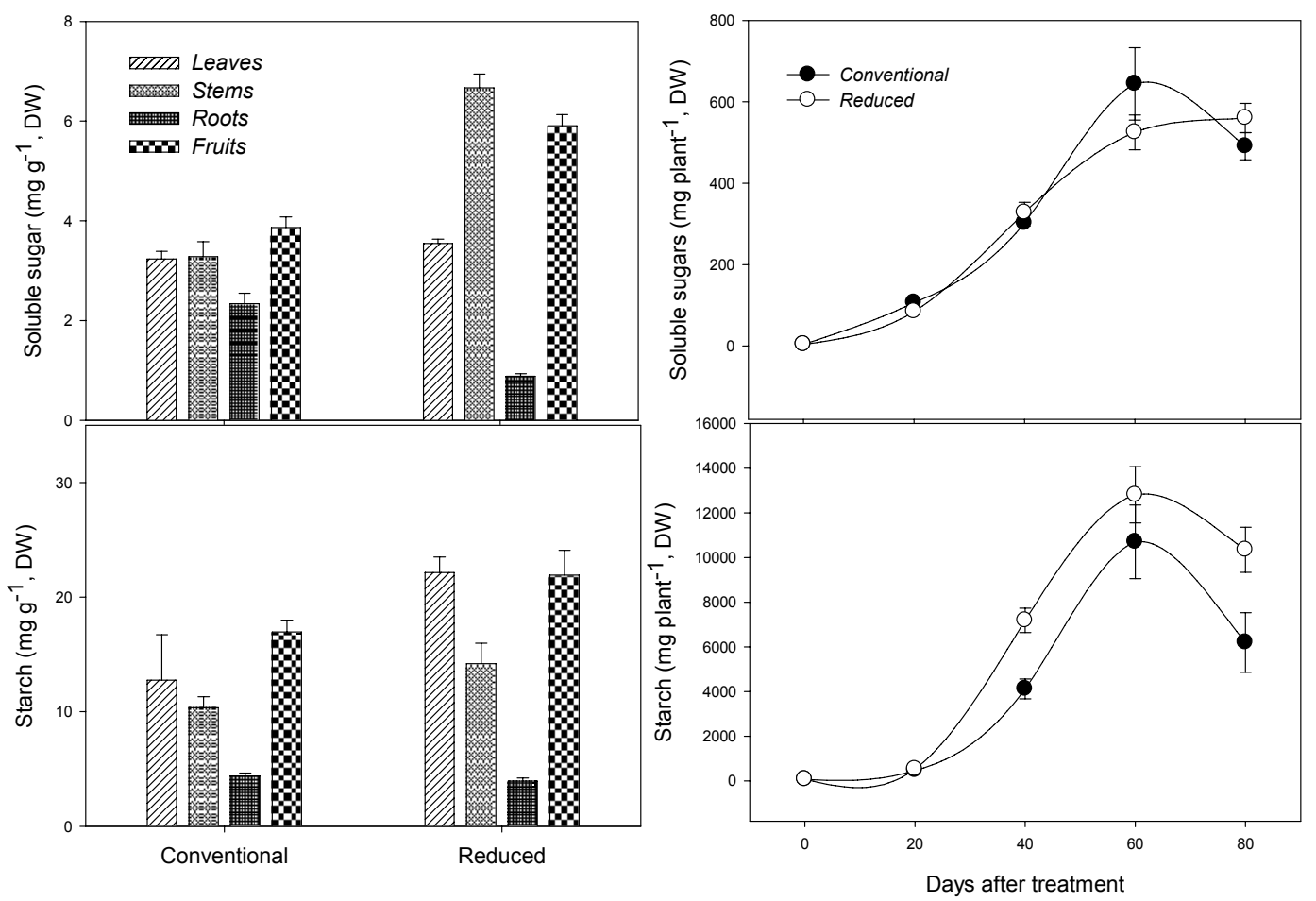

Fig. 4. Effects of the reduced supply of mineral nutrition on soluble sugars ( $\mathrm{mg} \mathrm{g}^{-1}$, dry weight) at 80 days after mineral supply and total biosynthesis (sum of leaves, stems, roots, and fruits, mg plant $^{-1}, \mathrm{DW}$ ) of tomato plants. Emor bars indicate standard deviations of four replicates.

8.6 $\left.\mu \mathrm{mol} \mathrm{m} \mathrm{m}^{-2} \mathrm{~s}^{-1}\right)$. The evaporation reached at the peak at 40 DAT and declined, but the stomatal conductance in the conventional represented a constant increase, although remained unchanged in the reduced. The contents (glucose equi.) of soluble sugars and starch greatly differed with plant organs and it was strongly affected by mineral application (Fig. 4). The soluble sugar levels in the reduced were higher in stems $\left(6.7 \pm 0.3 \mathrm{mg} \mathrm{g}^{-1}\right)$ and fruits $(5.9 \pm 0.2$ $\left.\mathrm{mg} \mathrm{g}^{-1}\right)$ compared to the conventional $\left(3.3 \pm 0.2 \mathrm{mg} \mathrm{g}^{-1}\right.$ and $3.9 \pm 0.2 \mathrm{mg} \mathrm{g}^{-1}$, respectively), whereas less in roots. Total accumulation of soluble sugars did not show any significant difference between treatments during the whole experiment, and their levels gradually increased, peaked at 60 DAT, and decreased or unchanged. The starch was more accumulated in leaves $\left(22.2 \pm 1.4 \mathrm{mg} \mathrm{g}^{-1}\right.$, dry weight), stems $\left(14.2 \pm 1.8 \mathrm{mg} \mathrm{g}^{-1}\right)$ and fruits $(2.9 \pm 2.2$ $\left.\mathrm{mg} \mathrm{g}^{-1}\right)$ in the reduced than those in the conventional $\left(12.8 \pm 4.0 \mathrm{mg} \mathrm{g}^{-1}, 10.4 \pm 1.0 \mathrm{mg} \mathrm{g}^{-1}\right.$ and $17.0 \pm 1.0 \mathrm{mg} \mathrm{g}^{-1}$, respectively). The accumulation of starch throughout the experiment showed a sigmoid curve in both treatments, but the gap, which means that the reduced in starch accumulation exceeds the conventional, was initiated after 20 DAT. Also, the accumulation of starch peaked at 60 DAT and then sharply decreased in both treatments.

Proportion of minerals and soluble carbohydrates by organs The proportion of minerals $(\mathrm{N}, \mathrm{P}$ and $\mathrm{K})$ and
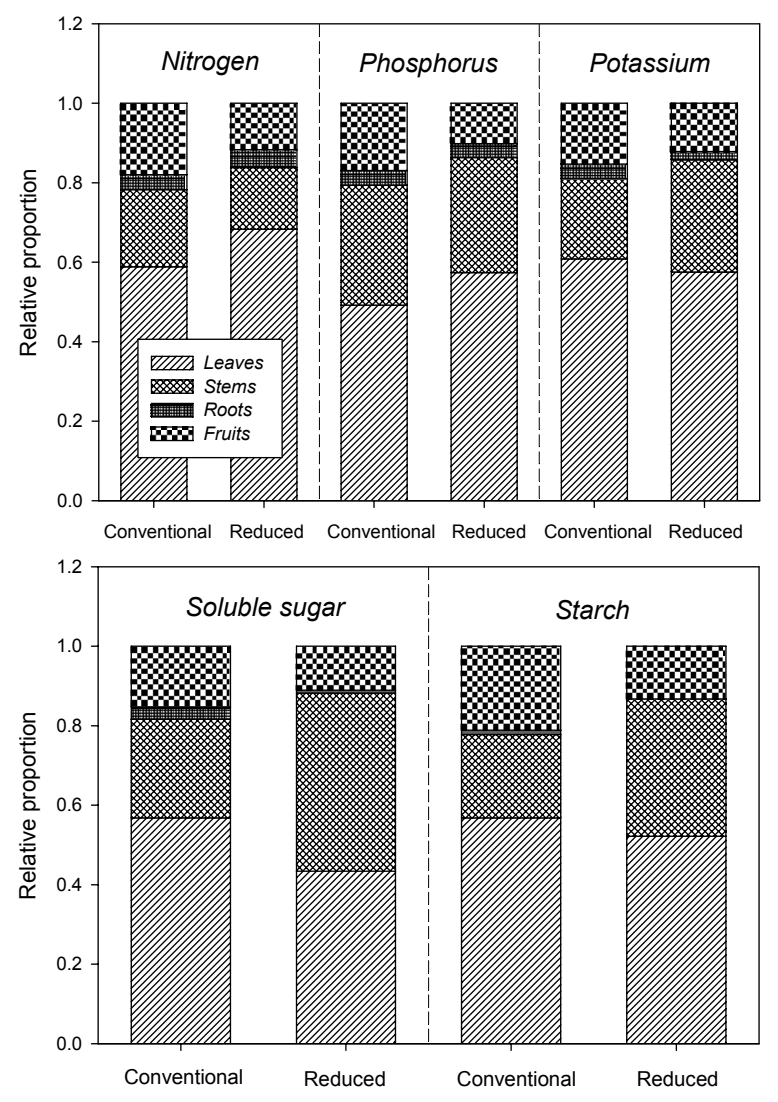

Fig. 5. Comparison between conventional and reduced supply on the relative proportion of $\mathrm{N}, \mathrm{P}, \mathrm{K}$, soluble sugar and starch by organs of tomato plants. 
soluble carbohydrates (soluble sugars and starch) by organs at 80 DAT was examined (Fig. 5). Compared to the conventional, nitrogen and phosphorus in the leaves of the reduced took relatively high possession, and potassium occupied highly in the stems. Overall, the possession of minerals was the highest in the leaves and followed by stems, fruits and roots. The soluble sugar and starch in the reduced were predominant in the stems compared to the conventional. The occupancy of leaves, roots and fruits were relatively lower in the reduced than in the conventional.

\section{Discussion}

Enhancing the utilization of minerals deposited excessively in greenhouse soils is one of the first considerations to not only reduce the overdose of chemical fertilizers, but also improve an agricultural-environment. In this study, we used greenhouse soil which chemical properties were substantially higher compared to the recommended optimal level. The shoot growth rates of tomato did not show a statistical difference in the reduced application of chemical fertilizer (Hoagland's solution) until 80 days after treatment (DAT) (Fig. 1). However, growth in the reduced after 60 DAT seemed to be gradually decreased; daily growth in the conventional was $1.48 \mathrm{~g}$ day $^{-1}$, whereas $0.82 \mathrm{~g} \mathrm{day}^{-1}$ in the reduced which reach only $55 \%$ of the conventional. Our result found that farmer's fertigation initiation (usually 14 days after transplanting) did not take an advantage of favorable crop growth if soil chemical properties are distinctly higher, rather, it is better to begin between 40 to 50 days after transplanting.

The retranslocation of mineral nutrients from shoot to roots is at least involved in the preferential partitioning of carbon to the roots under conditions of limited nutrient supply to roots from the external medium (Marschner et al., 1996). The reduced fertilizer application led to a substantial decrease in $\mathrm{N}, \mathrm{P}$ and $\mathrm{K}$ concentrations in fruits at 80 DAT, whereas remained constant in other organs, and, also, a significant difference in their uptake represented after 40 DAT (Fig. 2). The uptake of N, P and K in the reduced treatment was 61,70 and $76 \%$, respectively, compared to the conventional at 80 DAT. A decrease in mineral translocation towards the fruits was assumed that minerals in the source leaves mainly headed to rather the roots or shoot apices than the fruits to ensure continuous mineral uptake from the external medium. This result is in agreement with the previous finding which retranslocation of $\mathrm{N}, \mathrm{P}$ and $\mathrm{K}$ from the shoot to the roots is greatly enhanced to cover high demand for root growth and to act as an important signal for nutrient uptake (Drew and Saker, 1984; Drew et al., 1984; Drew et al., 1990; Marshner et al., 1996). Furthermore, we found that mineral uptake of tomato plants is greater influenced by the concentration than by growth rates. Nutrient deficiency may not only affect the provision of photosynthates by decreasing source capacity, but also by altering photosynthate partitioning between the source leaves and various sinks. The $\mathrm{CO}_{2}$ fixation decreased gradually in the reduced, and thus represented the reduction in 30\%, which means daily reduction in 0.7 to $0.8 \%$ at 60 DAT (Fig. 3). A decrease in $\mathrm{CO}_{2}$ fixation showed to be closely associated with mineral uptake, because both results represented significant difference after 40 DAT. The reduced application led to great differences in the concentration and partitioning of soluble carbohydrates (Fig. 4). In our study, soluble sugar concentration in the reduced greatly increased in stems and fruits at 80 DAT, whereas drastically decreased in roots. Lower nutrient condition resulted in favorable transportation of soluble sugar via phloem exporting rather towards fruits (sink) than roots (sink) from leaves (source) and higher interception of stems. On the other hand, starch concentration in the reduced was elevated in leaves, stems and fruits, whereas remained unchanged in the roots. It is well documented that $\mathrm{N}$ and $\mathrm{P}$ deficiencies lead to the preferential accumulation of soluble carbohydrates in the source leaves, and then phloem export to the roots which increases root-shoot ratio (Fredeen et al., 1989; Cakmak, 1994; Peuke et al., 1994). On the contrary, K deficiency decreases R:S ratio because of impaired photosynthate export despite of the accumulation of carbohydrates in the source leaves (Fischer and Bremer, 1993). In our previous study, mineral deficiencies of $\mathrm{N}, \mathrm{P}$ and $\mathrm{K}$ led to an accumulation of soluble carbohydrates such as soluble sugar and starch in both shoot and roots, and negative interaction between minerals and carbohydrates (Sung et al., 2013, in press). Thus, our present results with not only leaves and roots, but also stems and fruits could be assumed a possible hypothesis as follows; lower utilization of soluble carbohydrates towards the biosynthesis of primary and secondary metabolites caused an accumulation not only in stems and fruits, but also in leaves. Total synthesized amount of soluble sugar was not significant between treatments during the whole experiment, whereas the difference in starch amount showed after 20 DAT, and starch levels were higher in the reduced because lower utilization. The allocation of mineral $\mathrm{N}, \mathrm{P}$ and $\mathrm{K}$ and soluble carbohydrates by plant organs based on the result at 80 DAT was estimated (Fig. 5), and more than $50 \%$ of minerals and soluble carbohydrates was occupied in leaves. The shortage of mineral supply increased the proportion of $\mathrm{N}$ and $\mathrm{P}$ in leaves and $\mathrm{K}$ in stems, and led to high accumulation of soluble sugar and starch in stems. However, sufficient mineral supply made to increase the allocation in fruits although the proportion to total amount was relatively low. 
In conclusion, our study suggests that the initiation of the fertigation might be delayed without an adverse effect on crop growth if the soil highly accumulates mineral elements as we reported here that a better initiation time is between 40 to 50 DAT. Also, it is expected that tomato fruits without a significant fall will be harvested although we do not present the yield data.

\section{References}

Atallah T., T. Darwish, and M. El Moujabber. 2002. Modality of fertigation of protected cucumber and nitrogen use efficiency under field conditions. In Water Balance: Fertigation for Crop Improvement in West Asia. Results of a Technical Cooperation Project, IAEA-TECDOC-1266, Ed. International Atomic Energy Agency, pp. 41-48. IAEA, Vienna.

Atallah T., T. Darwish, and R. Ward. 2000 Modality of fertigation of protected cucumber and nitrogen use efficiency in closed systems. Leb. Sci. J., 1:27-32.

Cakmak, I., Ch. Hengeler, and H. Marshner. 1994. Partitioning of shoot and root dry matter and carbohydrates in bean plants suffering from phosphorus, potassium and magnesium deficiency. Journal of Experimental Botany 45:1245-1250.

Cakmak, I. 1994. Activity of ascorbate-dependent $\mathrm{H}_{2} \mathrm{O}_{2}$-scavenging enzymes and leaf chlorosis are enhanced in magnesium- and potassium-deficient leaves, but not in phosphorus-deficient leaves. Journal of Experimental Botany 45:1259-1266.

Cannell, M.G.R. and R.C. Dewar. 1994. Carbon allocation in trees: a review of concepts for modeling. Advances in Ecological Research 25:60-102.

Dewar, R.C. 1993. A root-shoot partitioning model based on carbon-nitrogen-water interactions and Münch phloem flow. Functional Ecology 7:356-368.

Drew, M.C. and L.R. Saker. 1984. Uptake and long-distance transport of phosphate, potassium and chloride in relation to internal ion concentrations in barley: evidence of non-allosteric regulation. Planta 160:500-507.

Drew, M.C., J. Webb, and L.R. Saker. 1990. Regulation of $\mathrm{K}^{+}$ uptake and transport to the xylem in barley roots: $\mathrm{K}^{+}$ distribution determined by electron probe $\mathrm{X}$-ray microanalysis of frozen-hydrated cells. Journal of Experimental Botany 41:815-822.

Drew, M.C., L.R. Saker, S.A. Barber, and W. Jenkins. 1984. Changes in the kinetics of phosphate and potassium absorption in nutrient-deficient barley roots measured by a solutiondepletion technique. Planta 160:490-499.

Fredeen, A.L., I.M. Rao, and N. Terry. 1989. Influence of phosphorus nutrition on growth and carbon partitioning in Glycine max. Plant Physiology 89:225-230.

Fischer, E.S. and E. Bremer. 1993. Influence of magnesium deficiency on rates of leaf-expansion, starch and sucrose accumulation, and net assimilation in Phaseolus vulgaris. Physiologia Plantarum 89:271-276.

Lewin, S.A., H.A. Mooney, and C. Field. 1989. The dependence of plant root:shoot ratios on internal nitrogen concentration. Annals of Botany 64:71-75.

NAAS. 2010. Standard fertilization by crops. pp. 64.

NAAS. 2012. The report: Monitoring project on agro-environmental quality. pp. 50-51.

Peuke, A.D. and W.D. Jeschke. 1993. The uptake and flow of C, $\mathrm{N}$ and ions between roots and shoots in Ricinus communis L. I. Grown with ammonium or nitrate as nitrogen source. Journal of Experimental Botany 44:1167-1176.

Sung, J.K., S.M. Lee, S.Y. Lee, R.Y. Kim, Y.J. Lee, H.B. Yun, S.K. Ha, and B.H. Song. 2013. Effect of suboptimal nutritional status on mineral uptake and carbohydrate metabolism in tomato plants. Korean Journal of Soil Science and Fertilizer 46 (in press).

Yu, H.Y., T.X. Li, and J.M. Zhou. 2004. Salt accumulation, translocation and ion composition in greenhouse soil profiles. Plant Nutr. Ferti. Sci., 41:822-826. 